\title{
SUCTION BLISTER GRAFTING- STILL A USEFUL MODALITY FOR TREATMENT OF RESISTANT AND STABLE VITILIGO
}

\author{
S. Srinivasa Ravi1 ${ }^{1}$, Syama Sundari Chittoory²
}

${ }^{1}$ Assistant Professor, Department of DVL, Rangaraya Medical College, Kakinada.

${ }^{2}$ Senior Resident, Department of DVL, Guntur Medical College, Guntur.

ABSTRACT
BACKGROUND
Vitiligo is a common depigmentation disorder due to absence of functional melanocytes in the affected area. Depending on the
type, extent and duration of vitiligo, conventional medical therapies and phototherapy are used. Medical treatment is effective in
only $60 \%-70 \%$ of the patients. This has led to the evolution of various surgical modalities to treat recalcitrant stable lesions.
The aim of this study was to determine the efficacy of suction blister grafts for treatment of recalcitrant and stable vitiligo.

\section{MATERIALS AND METHODS}

This study was conducted on 20 patients with stable vitiligo. They included lip vitiligo ( 6 cases), segmental vitiligo (6 cases) and focal vitiligo (8) that were resistant to conventional medical treatments. Manual suction with $20 \mathrm{cc}$ disposable syringes for blisters at donor site and dermabrasion at recipient site was done. The blister was separated, fixed at recipient site and dressing was done followed by NBUVB thrice a week for 3 months. Repigmentation of lesions was evaluated monthly for 6 months after treatment. Repigmentation rates $>90 \%, 71 \%-90 \%, 51 \%-70 \%$ and $<50 \%$ were graded as complete, good, moderate and poor respectively.

\section{RESULTS}

This study includes 20 patients (10 female and 10 male) with stable vitiligo were evaluated for response following suction blister grafting with thrice weekly post-graft phototherapy. Reponses to treatment after a 6-month followup were 'complete,' 'good' and 'moderate' in 12 (60\%), 6 (30\%) and $2(10 \%)$ patients respectively and one patient was lost for followup.

\section{CONCLUSION}

The grafting procedures in vitiligo are performed for cosmetic purposes. Proper selection of the patient is the most important factor for achieving a good cosmetic result. Stability of the disease process is the most important parameter to achieve a successful outcome. Suction blister grafting gives excellent cosmetic results with minimal chances of scarring at the donor or recipient sites.

\section{KEYWORDS}

Suction Blister Grafting, Vitiligo, Stability, Repigmentation, NBUVB.

HOW TO CITE THIS ARTICLE: Ravi SS, Chittoory SS. Suction blister grafting- still a useful modality for treatment of resistant and stable vitiligo. J. Evolution Med. Dent. Sci. 2017;6(80):5668-5673, DOI: 10.14260/jemds/2017/1229

\section{BACKGROUND}

Around one percent of the world's population has vitiligo, a disease which causes white patches on the skin. There are a variety of treatments available, most of which are unsatisfactory.(1) Thus, there remains a group that is resistant to all the non-surgical means of treatment or in whom surgical therapy is considered to be more appropriate than medical means and led to the evolution of various modalities of surgical replacement of the damaged melanocytes to treat recalcitrant stable lesions.

These surgical techniques are collectively known as grafting procedures. The choice of the grafting procedure to be performed usually depends upon various factors like the extent or size of the vitiligo lesion to be treated, the site of the lesion, the age of the patient, his/her expectations and social needs, and lastly the expertise of the operating surgeon. $(2,3)$

'Financial or Other Competing Interest': None.

Submission 29-08-2017, Peer Review 24-09-2017,

Acceptance 30-09-2017, Published 05-10-2017.

Corresponding Author:

Syama Sundari Chittoory,

Flat No. 408, Ramabhanu Apartments,

Digumarthi Vari St

Kakinada-533001, Andhra Pradesh.

E-mail: syam.chittoory@gmail.com

DOI: $10.14260 /$ jemds $/ 2017 / 1229$

(c) (i) $(5)$
The Grafting Techniques in Vitiligo are divided into Two Main Groups-

i) Tissue grafting, and

ii) Cellular grafting(4,5,6) Table 1.

As such vitiligo is hardly a disease of medical significance, but there is more of a social stigma attached to it because of cosmetic reasons.(7) These grafting procedures in vitiligo are performed for cosmetic purposes and the ideal grafting procedure is one that gives the best cosmetic results. Epidermal grafting using the tops of suction blisters has been found to be the most effective surgical procedure. ${ }^{(8)}$

Proper selection of the patient is the most important factor for good cosmetic result. The factors that need to be considered are the age of the patient, the site of vitiligo, keloidal tendency and most importantly the stability of vitiligo.

Stability of vitiligo simply means that the disease process is no longer active in an individual patient. Clinically, stability is manifested as absence of new lesions, absence of spread of existing vitiligo lesions, and absence of Koebner's phenomenon. The minimum duration of stability for vitiligo grafting is still a debatable issue with the recommended minimum duration ranging from 6 months to as long as 4 years in different clinical studies.(9-11) Another debatable issue in this regard is that of patient versus lesional stability, but majority of researchers still 
favour patient stability over the lesional stability while selecting a patient for vitiligo grafting.

The IADVL task force has defined stability as the patient with no new lesions, no progression of existing lesions and absence of Koebner phenomenon during the past 1 year.(12) Therefore, the task force recommends that surgery for vitiligo should be performed only in patients with VIDA scores of -1 or 0(13) (Table 2).

Thus, this study was taken for the determination of efficacy of suction blister grafting technique in the treatment of stable (inactive since 1 year) and resistant (in responsive to conservative treatments) vitiligo.

\section{MATERIALS AND METHODS}

This study includes 20 patients with limited vitiligo that was in stable state but resistant to different medical treatments, attending DVL OP of Government General Hospital, Kakinada from July 2014 to June 2017. Suction blister grafting was done with informed consent. The study was approved by Institutional Ethics Committee.

\section{Inclusion Criteria}

Patients attending to OPD with vitiligo stable for at least 1 year, non-responsive to medical treatment and willing for suction blister grafting were included in the study with informed consent.

\section{Exclusion Criteria}

Patients with either lesion or patient unstable or active vitiligo were excluded.

\section{Study Design}

This study is an uncontrolled clinical trial to establish the efficacy of suction blister grafting in the stable and conventional treatment resistant vitiligo lesions.

\section{Statistical Analysis}

To analyse the results, descriptive statistical analysis such as mean, standard deviation (SD) and Chi-square test to test the statistical significance between age, gender, site of lesion and stability with repigmentation were done. P-value 0.05 is taken as significant.

\section{Principle}

In suction blister grafting, cleavage occurs between the basal cells and the basal lamina of the basement membrane zone and only the epidermal portion of the donor area is grafted. This method is to transfer active melanocytes from donor area to recipient vitiligo lesions through blister induction, separation of epidermis and then transferring it to recipient area. In a few days, melanocytes penetrate into the recipient area and activate to produce pigmentation.(14) Hence, the graft generally acquires the characteristics of the recipient site, thus leading to a better colour match and cosmetic outcome.

\section{Methodology}

- All patients were advised to discontinue previous treatments for at least 4 weeks before the grafting procedure to minimise any possible drug effects.

- Donor Area: In this study, the donor site was taken from the flexor aspect of the forearm and the anterolateral aspect of the thigh (covered sites are preferred, as pigmentary changes can occur at the donor site).

- Preparation of Donor Area: On the day of surgery, a donor site with normal skin was selected and cleaned first with povidone iodine and then with normal saline. After surgical cleansing, a topical local anaesthetic (EMLA) is applied as the procedure is painful.

- $\quad$ Raise of Blisters: The device used for inducing a blister consisted of 20 and $50 \mathrm{~mL}$ syringes, three-way cannulas, a pressure gauge. $20 \mathrm{~mL}$ disposable syringes were used as suction cups. The piston of $20 \mathrm{cc}$ syringe is removed and 3-way cannula is attached to its needle end piece. The basal rim of this $20 \mathrm{cc}$ syringe is then applied to the fully stretched donor site. Suction was attempted by means of a $50 \mathrm{~mL}$ syringe attached to the opposite end of the 3-way cannula. Vacuum was retained by locking the suction syringe at the end of the three-way cannula. Once the desired pressure was attained, the suction syringe end was locked. Due to the negative pressure inside the basal rim of syringe, it remains adherent to the donor site in a vertical position along with the attached 3-way cannula. Multiple such 20 cc syringes ( 8 - 10 or more) can be applied similarly next to each other as per the area of recipient site required to be grafted. Negative pressure is retained for 1 - 2 hours. Time required for separation is 45 mins. to 2 hours.

- Deroofing the Blister: Once the blisters are well formed, the roofs of the blisters are gently cut using scalpel blade and was put in a normal saline containing petri dish with roofs everted onto a glass slide, such that the dermal side faces upwards. The graft is then cleaned, spread to its maximum size and smeared with antibiotic cream which prevents wrong placement of epidermal side and infection. Always keep the graft moist with normal saline.

- The donor site was dressed with antibiotic ointment and vaseline gauze.

- Recipient Site: While dressing the donor site, another person prepares the recipient site for grafting. The site (vitiliginous macule) is surgically cleansed and anaesthetised with $1 \%$ lignocaine. The site is dermabraded using a motor dermabrader till minute pinpoint bleeding spots are visible and dermabrasion is done $1-2 \mathrm{~mm}$ beyond the vitiliginous area.

- Transfer of the Graft: Over the dermabraded recipient area, the glass slide with graft is inverted such that the dermal side of the graft is in contact with recipient area. Each graft is transferred individually, so that a gap of 0.5 $\mathrm{cm}$ is left between two grafts for pigment spread. Graft is placed such that edges extend $1-2 \mathrm{~mm}$ beyond the vitiligo area.

- Dressing: To prevent the chance of misplacement of the graft wet sterile cotton was placed over the area, covered with sterile gauze and then firmly bandaged with Dynaplast.

- Postoperative Care: After surgery, a week's course of oral antibiotic (Cefixime $200 \mathrm{mg}$ BD) was given and the patient was instructed to keep the grafted site immobile for a week. 
- Dressing over recipient area was changed after a week, but dressing over donor area was removed next day and cleaned daily. Scaling of the site was observed as the graft fall off in 1 - 2 weeks.

- Follow-Up: The patient was asked to come for NBUVB from the day of removal of the dressing for thrice a week for at least 3 months.

- Repigmentation of lesions was evaluated monthly for 6 months after treatment.

- Grading of repigmentation rates > 90\%, 71\% - 90\%, $51 \%-70 \%$ and $<50 \%$ were as complete, good, moderate and poor respectively.

\section{RESULTS}

20 patients (10 female and 10 male) with stable vitiligo were evaluated for response following suction blister grafting with thrice weekly post-graft phototherapy. The mean age of male patients and female patients in this study was $27.7 \pm 3.26$ and $22.4 \pm 3.33$ respectively. The mean period of stability of lesions (in terms of months) in this study was $14.5 \pm 2.6$. Statistical analysis is done by Chi-square test to test the statistical significance between age, gender, site of lesion and stability with repigmentation. There is statistically no significant difference in repigmentation between male and female (Table 3), stability (months) and repigmentation (Table 5), site of the lesion and repigmentation (Table 6) and age and repigmentation (Table 7).

Initial signs of repigmentation were noticed after $4-6$ weeks. After 6 months of followup, complete repigmentation (> 90\%) occurred in 12 patients and repigmentation of around $90 \%-71 \%$ is seen in 6 patients, repigmentation of $70 \%-51 \%$ in 2 patients. The response to treatment after 6 months of follow-up is represented on clinical basis as moderate, good and complete responses were found in $10 \%$, $30 \%$ and $60 \%$ of patients respectively in Table 4 .

\begin{tabular}{|c|c|}
\hline \multicolumn{2}{|c|}{ Grafting Techniques } \\
\hline Tissue Grafts & Cellular Grafts \\
\hline Minipunch grafting & \\
Suction blister grafting & \\
Thin split thickness & Non-cultured basal cell \\
grafting & suspensions \\
Hair follicle grafts & Cultured melanocytes/ \\
Mesh grafts & keratinocyte grafts \\
Flip-top pigment & \\
Transplantation & \\
\hline \multicolumn{2}{|c|}{ Table 1 } \\
\hline
\end{tabular}

\begin{tabular}{|c|c|}
\hline \multicolumn{2}{|c|}{ VIDA 6-Point Score } \\
\hline Disease Activity & $\begin{array}{c}\text { VIDA } \\
\text { Score }\end{array}$ \\
\hline Active in past 6 weeks & +4 \\
\hline Active in past 3 months & +3 \\
\hline Active in past 6 months & +2 \\
\hline Active in past 1 year & +1 \\
\hline Stable for at least 1 year & 0 \\
\hline $\begin{array}{c}\text { Stable for at least 1 year and spontaneous } \\
\text { repigmentation }\end{array}$ & -1 \\
\hline Table 2 \\
\hline \multicolumn{2}{|c|}{}
\end{tabular}

\begin{tabular}{|c|c|c|c|c|c|c|}
\hline & \multicolumn{3}{|c|}{ Repigmentation } & \multirow{2}{*}{ Total } & \multirow{2}{*}{$\begin{array}{c}P- \\
\text { value }\end{array}$} \\
\hline & & Complete & Good & Moderate & & \\
\hline \multirow[b]{2}{*}{ Gender } & $\mathrm{F}$ & 6 & 3 & 1 & 10 & \\
\hline & M & 6 & 3 & 1 & 10 & $\begin{array}{l}1.000 \\
(\mathrm{NS})\end{array}$ \\
\hline \multicolumn{2}{|c|}{ Total } & 12 & 6 & 2 & 20 & \\
\hline \multicolumn{7}{|c|}{ Table 3. Gender-Repigmentation } \\
\hline
\end{tabular}

NS- Nil Significant.

\begin{tabular}{|c|c|c|}
\hline Repigmentation & Percentage & No. of Cases \\
\hline Complete & $>90 \%$ & $12(60 \%)$ \\
\hline Good & $71-90 \%$ & $6(30 \%)$ \\
\hline Moderate & $51-70 \%$ & $2(10 \%)$ \\
\hline Poor & $<50 \%$ & - \\
\hline \multicolumn{3}{|c|}{ Table 4 }
\end{tabular}

\begin{tabular}{|c|c|c|c|c|c|c|}
\hline \multirow{2}{*}{\multicolumn{2}{|c|}{$\begin{array}{l}\text { Stability } \\
\text { (Months) }\end{array}$}} & \multicolumn{3}{|c|}{ Repigmentation } & \multirow{3}{*}{$\begin{array}{c}\text { Total } \\
9\end{array}$} & \multirow{3}{*}{$\begin{array}{c}P \text { - } \\
\text { value }\end{array}$} \\
\hline & & Complete & Good & Moderate & & \\
\hline & 12 & 7 & 1 & 1 & & \\
\hline & 15 & 1 & 3 & 1 & 5 & $\begin{array}{c}0.235 \\
\text { (NS) } \\
\end{array}$ \\
\hline & 18 & 4 & 2 & 0 & 6 & \\
\hline \multicolumn{2}{|l|}{ Total } & 12 & 6 & 2 & 20 & \\
\hline
\end{tabular}

NS- Nil Significant.

\begin{tabular}{|c|c|c|c|c|c|c|}
\hline & \multicolumn{3}{|c|}{$\begin{array}{l}\text { Repigmentati } \\
\text { on }\end{array}$} & \multirow[b]{2}{*}{ : } & \multirow[b]{2}{*}{ 苞 } \\
\hline & & 苞 & T⿱乛口 & 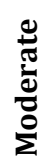 & & \\
\hline \multirow{11}{*}{$\begin{array}{l}\text { Site of } \\
\text { the } \\
\text { lesion }\end{array}$} & $\begin{array}{l}\text { Anterior } \\
\text { aspect of } \\
\text { chest }\end{array}$ & 0 & 1 & 0 & 1 & \\
\hline & $\begin{array}{l}\text { Dorsum of } \\
\text { right foot }\end{array}$ & 0 & 0 & 1 & 1 & \\
\hline & Forehead & 2 & 0 & 0 & 2 & \\
\hline & $\begin{array}{c}\text { Left } \\
\text { forearm }\end{array}$ & 1 & 0 & 0 & 1 & \\
\hline & Left leg & 1 & 0 & 1 & 2 & \\
\hline & Lower lip & 5 & 0 & 0 & 5 & \\
\hline & $\begin{array}{l}\text { Posterior } \\
\text { aspect of } \\
\text { right ear }\end{array}$ & 1 & 0 & 0 & 1 & $\begin{array}{c}0.085 \\
\text { (NS) }\end{array}$ \\
\hline & $\begin{array}{c}\text { Right } \\
\text { forearm }\end{array}$ & 0 & 1 & 0 & 1 & \\
\hline & Right leg & 2 & 2 & 0 & 4 & \\
\hline & $\begin{array}{l}\text { Right side } \\
\text { of neck }\end{array}$ & 0 & 1 & 0 & 1 & \\
\hline & Right thigh & 0 & 1 & 0 & 1 & \\
\hline \multicolumn{2}{|c|}{ Total } & 12 & 6 & 2 & 20 & \\
\hline
\end{tabular}

NS- Nil Significant. 


\begin{tabular}{|c|c|c|c|c|c|}
\hline \multirow{2}{*}{$\begin{array}{c}\text { Age } \\
\text { in yrs. }\end{array}$} & \multicolumn{3}{|c|}{ Repigmentation } & \multirow{2}{*}{ Total } & P-value \\
\cline { 2 - 6 } & Complete & Good & Moderate & & \\
\hline$<25$ yrs. & 5 & 2 & 1 & 8 & $0.901(\mathrm{NS})$ \\
\hline$\geq 25$ yrs. & 7 & 4 & 1 & 12 & \\
\hline Total & $\mathbf{1 2}$ & $\mathbf{6}$ & $\mathbf{2}$ & $\mathbf{2 0}$ & \\
\hline \multicolumn{6}{|c|}{ Table 7. Age- Repigmentation } \\
\hline
\end{tabular}

NS- Nil Significant.

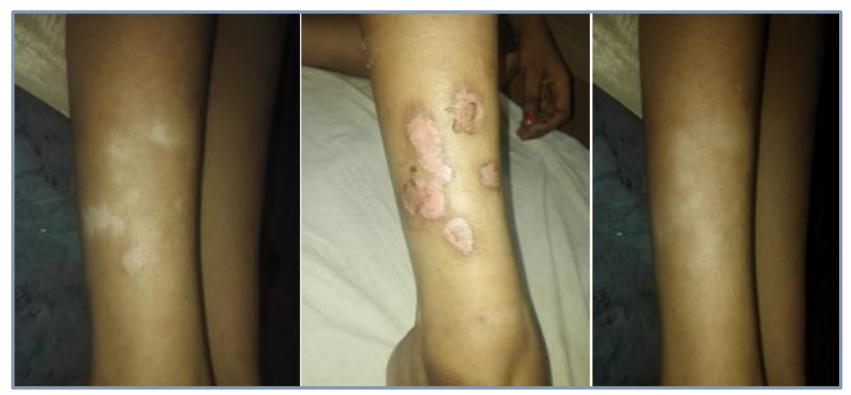

Figure 1. Pre-Grafting, Suction Blister Grafting done after 3 Months

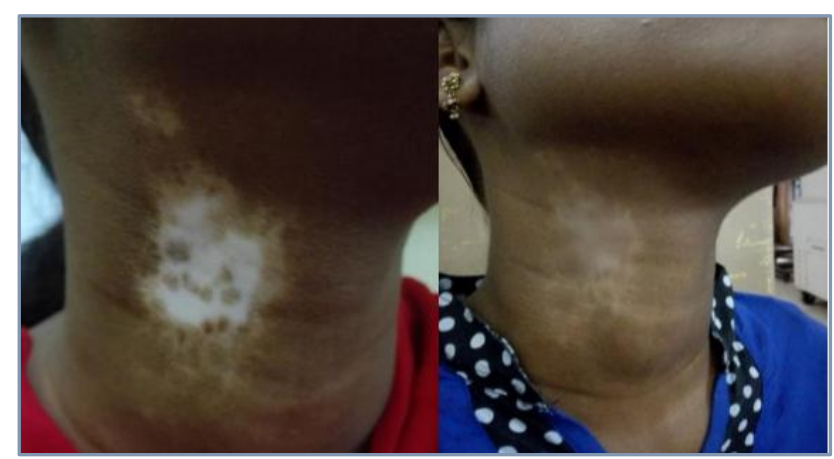

Figure 2. Lesion before Grafting after 3 Months

\section{DISCUSSION}

Vitiligo is a fairly common pigmentary disorder of skin resulting from a loss of melanin which causes depigmented skin, mucous membrane, eyes and sometimes hair bulbs. The cause of melanocyte destruction has remained unclear,(15) but several theories have tried to explain the pathogenesis of vitiligo such as autoimmunity,(16) self-destructing mechanisms,(17) neurals,(18) biochemical,(19) an imbalance of epidermal cytokines(20) and genetic factors.(21)

Vitiligo is not a life-threatening disease; however, it frequently induces emotional distress.(22) Vitiligo should initially be treated with medical therapy. When the therapy fails in spite of all appropriate interventions, surgical treatment may be indicated.(23) Njoo et al recommended a surgical technique as first line treatment of segmental vitiligo and vitiligo involving lips and finger tips.(24) The site of lesions also determines the degree of success of surgical treatment. For instance, the success rates of vitiligo treatments on finger and elbow are considerably lower than those on other sites. The patient's motivation is also an important factor to be considered.(25)

Autologous skin grafts can be obtained from uninvolved skin using several techniques including a number of dermatosurgery techniques.(26) Each method has its advantages and disadvantages. Suction blister grafting is an effective, nonscarring, surgical repigmentation method that has become popular since 1971 when Falabella first described its use in leukoderma.(27) Suction blister grafting is accomplished by suction of viable epidermis from dermis and pigmented epidermis is used for coverage of achromic areas. Essentially, this is a technique of melanocyte transfer.

At the recipient site, separation of epidermis from the underlying dermis is done till pinpoint bleeding is seen, which is approximately at the dermo-epidermal junction. Removal of the epidermal layer permits plasmatic imbibition for the first 24 to 48 hours and then thereafter vascular ingrowth provides cellular nutrition.(28) In most of the studies in the literature, after completion of epithelialisation (i.e. usually after 1 week) phototherapy was used to induce proliferation and migration of melanocytes in the recipient sites.(29-31) The repigmentation rate in these studies according to the review by Njoo et al was $87 \%$, whereas Ozdemi et al reported rates between 25\% - 65\%.(29-36) In the study by Maleki et al, ten patients with refractory vitiligo who were treated by suction blister graft and subsequent PUVA therapy reported over $90 \%$ repigmentation in seven patients. In studies of blister grafting followed without phototherapy, i.e. Nanda et al evaluated six patients with resistant eyelid vitiligo reported repigmentation in all cases( ${ }^{37)}$ and in another study by Maleki et al showed excellent results in $70 \%$ of patients. ${ }^{(38)}$

\section{Advantages}

Major advantage is as graft is very thin and purely epidermal, so minimal chances of scarring at both the donor or recipient sites with excellent cosmetic results especially for vitiligo over eyelids, lips, areola and genitals. Other benefits are no stuck-on effect, no depigmentation, cost effective, simple and safe technique. More importantly it offers a high mean success rate.(39) Scar formation, keloid, cobblestoning, sinking pits, thick margins and milia formation was much less compared to split thickness grafting or punch grafting.(33)

\section{Disadvantages}

It is time consuming, as donor site blistering requires a few hours. In the present study, the time to raise blisters was $3-4$ hours. Blister formation takes more time and is difficult to perform when the patients are young individuals. The weak dermoepidermal adherence found in aged persons makes the separation easier and faster.(14) The other disadvantages are it is not suitable for large areas, folded areas, palms and soles. Also requires specific attention, as epidermal grafting is very easy to tear or to roll up and leads to failure of repigmentation.

In our present study, suction blister grafting followed by thrice weekly phototherapy with NBUVB outcome was complete response, i.e. more than $90 \%$ repigmentation was seen in $60 \%$, good response i.e. about $90 \%-71 \%$ of repigmentation in $30 \%$ and around $10 \%$ patients showed moderate response i.e. $51 \%$ $70 \%$ of repigmentation.

\section{CONCLUSION}

Vitiligo causes photosensitivity, severe cosmetic distress, profound psychological impact, great social stigma and affects the quality of life. Surgical methods of treatment for vitiligo constitute an important adjuvant for patients unresponsive to medical therapy. Proper case selection based on the determination of stability of the lesions is very important. Above all proper patient counselling, both about the nature of the disease and the surgery is essential. Our study shows that suction blister grafting technique followed 
by thrice weekly phototherapy is effective, easy, facile and safe for treating stable and limited vitiligo.

\section{Limitations}

Our study had limitation of small sample size as many patients were not willing to undergo the procedure considering the pain (accompanying suction blister graft technique), the relatively long time needed for the procedure at present, also patients with larger lesions as they need multiple grafts to cover the lesional area and also those whose disease was in an unstable condition were excluded from the study.

Further studies were needed to get the clear consensus on the efficacy of suction blister grafting. Further research needed for finding methods to reduce pain and shorten the time required for blister induction could be valuable.

\section{ACKNOWLEDGEMENT}

We sincerely thank the participants for their help in conducting the study.

\section{REFERENCES}

[1] Whitton ME, Pinart M, Batchelor J, et al. Interventions for vitiligo. Cochrane Database of Systematic Reviews 2010;(1):CD003263.

DOI: 10.1002/14651858.CD003263.pub4.

[2] Njoo MD, Westerhof W, Bos JD, et al. A systematic review of autologous transplantation methods in vitiligo. Arch Dermatol 1998;134(12):1543-9.

[3] Gupta S, Kumar B. Epidermal grafting in vitiligo: Influence of age, site of lesion, and type of disease on outcome. J Am Acad Dermatol 2003;49(1):99-104.

[4] Löntz W, Olsson MJ, Moellmann G, et al. Pigment cell transplantation for treatment of vitiligo: a progress report. J Am Acad Dermatol 1994;30(4):591-7.

[5] Falabella R. Surgical treatment of vitiligo: why, when and how? J Eur Acad Dermatol Venereol 2003;17(5):518-20.

[6] Khunger N, Kathuria SD, Ramesh V, et al. Tissue grafts in vitiligo surgery: past, present and future. Indian J Dermatol 2009:54(2):150-8.

[7] Pandve HT. Vitiligo: is it just a dermatological disorder? Indian J Dermatol 2008;53(1):40-1.

[8] Gupta S, Kumar B. Epidermal grafting for vitiligo in adolescents. Pediatr Dermatol 2002;19(2):159-62.

[9] Juhlin L. How unstable is the concept of stability in surgical repigmentation of vitiligo. Dermatology 2000;201(2):183.

[10] Lahiri K, Malakar S. The concept of stability of vitiligo: a reappraisal. Indian J Dermatol 2012;57(2):83-9.

[11] Lahiri K. Stability in vitiligo? What's that? J Cutan Aesthet Surg 2009;2(1):38-40.

[12] Parsad D, Gupta S, IADVL Dermatosurgery Task Force. Standard guidelines of care for vitiligo surgery. Indian J Dermatol Venereol Leprol 2008;(Suppl 74):S37-45.

[13] Njoo MD, Das PK, Bos JD, et al. Association of the Kobner phenomenon with disease activity and therapeutic responsiveness in vitiligo vulgaris. Arch Dermatol 1999;135(4):407-13.
[14] Maleki M, Javidi Z, Ebrahimi-rad M, et al. Treatment of vitiligo with blister grafting technique. Iranian Journal of Dermatology 2008;11(2):55-9.

[15] Drake LA, Dinehart SM, Farmer ER, et al. Guidelines of care for vitiligo. American Academy of Dermatology. J Am Acad Dermatol 1996;35(4):620-6.

[16] Ongenae K, van Geel K, Naeyaert JM. Evidence for autoimmune pathogenesis of vitiligo. Pigment Cell Res 2003;16(2):90-100.

[17] Yee C, Thompson JA, Roche P, et al. Melanocyte destruction after antigen - specific immunotherapy of melanoma: direct evidence of $t$ cell-mediated vitiligo. J Exp Med 2000;192(11):1637-44.

[18] Taneja A. Treatment of vitiligo. J Dermatolog Treatment 2002;13(1):19-25.

[19] Schallreuter KU, Wood JM, Pittelkow MR, et al. Regulation of melanin biosynthesis in the human epidermis by tetrahydrobiopterin. Science 1994;263(5152):1444-6.

[20] Moretti S, Spallanzani A, Amato L, et al. New insight into pathogenesis of vitiligo: imbalance of epidermal cytokines at sites of lesions. Pigment Cell Res 2002;15(2):87-92.

[21] Kim SM, Chung HS, Hann SK. The genetics of vitiligo in Korean patients. Int J Dermatol 1998;37(12):908-10.

[22] Kovacs SO. Vitiligo. J Am Acad Dermatol 1998;38(5 Pt 1):647-68.

[23] Anstey AV. Disorders of skin colour. In: Burns T, Breathnach S, Cox N, et al. eds. Rook's Textbook of dermatology. Vol. 58. Hoboken New Jersey: Wiley Blackwell 2010:47-50.

[24] Njoo MD, Westerhof W, Bos D, et al. The development of guidelines for the treatment of vitiligo. Arch Dermatol 1999;135(12):1514-21.

[25] Njoo MD, Bossuyt PM, Westerhof W. Management of vitiligo: results of questionnaire among dermatologist in The Netherlands. Int J Dermatol 1999;38(11):86672.

[26] Halder RM, Taliaferro SJ. Vitiligo. In: Wolff K, Goldsmith LA, Katz SI, et al. eds. Fitzpatrick's dermatology in general medicine. New York: McGrawHill 2008:611-22.

[27] Falabella R. Epidermal graft. An original technique and its application in achromic and granulating areas. Arch Dermatol 1971;104(6):592-600.

[28] Al-Hadidi N, Griffith JL, Al-Jamal MS, et al. Role of recipient-site preparation techniques and postoperative wound dressing in the surgical management of vitiligo. J Cutan Aesthet Surg 2015;8(2):79-87.

[29] Lee AY, Jang JH. Autologous epidermal grafting with PUVA-irradiated donor skin for the treatment of vitiligo. Int J Dermatol 1998;37(7):551-4.

[30] Ortonne JP, MacDonald DM, Micoud A, et al. PUVAinduced repigmentation of vitiligo: a histochemical (split-DOPA) and ultrastructural study. Br J Dermatol 1979;101(1):1-12.

[31] Awad SS, Abdel-Raof H, El-Din HW, et al. Epithelial grafting for vitiligo requires ultraviolet A phototherapy to increase success rate. J Cosmet Dermatol 2007;6(2):119-24. 


\section{Jemds.com}

[32] Hann SK, Im S, Bong HW, et al. Treatment of stable vitiligo with autologous epidermal grafting and PUVA. J Am Acad Dermatol 1995;32(6):943-8.

[33] Suga Y, Butt KI, Takimoto R, et al. Successful treatment of vitiligo with PUVA-pigmented autologous epidermal grafting. Int J Dermatol 1996;35(7):518-22.

[34] Babu A, Thappa DM, Jaisankar TJ. Punch grafting versus suction blister epidermal grafting in the treatment of stable lip vitiligo. Dermatol Surg 2008;34(2):166-78.

[35] Rusfianti M, Wirohadidjodjo YW. Dermatosurgical techniques for repigmentation of vitiligo. Int J Dermatol 2006;45(4):411-7.

\section{Original Research Article}

[36] Ozdemir M, Cetinkale O, Wolf R, et al. Comparison of two surgical approaches for treating vitiligo: a preliminary study. Int J Dermatol 2002;41(3):135-8.

[37] Nanda S, Relhan V, Grover C, et al. Suction blister epidermal grafting for management of eyelid vitiligo: special consideration. Dermatol Surg 2006;32(3):38792.

[38] Maleki M, Banihashemi M, Sanjari V. Efficacy of suction blister epidermal graft without phototherapy for locally stable and resistant vitiligo. Indian J Dermatol 2012;57(4):282-4.

[39] Boersma BR, Westerhof W, Bos JD. Repigmentation in vitiligo vulgaris by autologous minigrafting: result in nineteen patients. J Am Acad Dermatol 1995;33(6):990-5. 